\title{
AS DISPARIDADES REGIONAIS FRENTE À CONSTRUÇÃO DE UM DIREITO COMUM EM ÂMBITO GLOBAL: O CASO DA AMÉRICA LATINA
}

\author{
Florisbal de Souza Del'Olmo ${ }^{1}$ \\ Evilhane Jum Martins ${ }^{2}$
}

\begin{abstract}
RESUMO
A pesquisa objetiva analisar os limites e possibilidades inerentes a construção de um direito comum global, evidenciando-se a natureza eurocêntrica deste pensamento, para então verificar a possibilidade de sua concretização, levando em conta as diferentes realidades a partir de uma averiguação desde a América Latina. Assim, quais as possibilidades para a construção de um direito comum global a partir de uma análise das peculiaridades da América Latina e do papel do movimento denominado Novo Constitucionalismo Latino-americano? Para responder utiliza-se a perspectiva sistêmica, os procedimentos foram a pesquisa bibliográfica e documental. A técnica cinge-se na construção de fichamentos e resumos estendidos.
\end{abstract}

Palavras-chave: Direito Comum. América Latina. Novo Constitucionalismo Latinoamericano.

\section{REGIONAL DISPARITIES FACE THE CONSTRUCTION OF A GLOBAL COMMON LAW: THE CASE OF LATIN AMERICA}

\begin{abstract}
The research aims to analyze the limits and possibilities inherent in the construction of a global common law evidencing the Euro-centric nature of this thought, to verify the possibility of its realization, taking into account the different realities from an ascertain based on Latin America. So, which are the possibilities for the construction of a global common law based on an analysis of the peculiarities of Latin America and the role of the movement called the New Constitutionalism Latin American? In order to answer the systemic perspective, the procedures were the bibliographical and documentary research. The technique girds itself in the construction of extended abstracts and book reports.
\end{abstract}

Keywords: Common Law. Latin America. New Constitutionalism Latin American.

\section{CONSIDERAÇÕES INICIAIS}

\footnotetext{
${ }^{1}$ Especialista em Direito e em Educação. Mestre (UFSC). Doutor em Direito (UFRGS) e Pós-Doutor em Direito (UFSC). Professor do Programa de Mestrado e Doutorado em Direito da URI, Santo Ângelo, RS, onde ministra a disciplina Direito Internacional e Interação na América Latina. Autor de Curso de Direito Internacional Privado, 12a edição, Editora Forense, 2017. Líder do Grupo de Pesquisa registrado no CNPq Tutela dos Direitos e sua Efetividade. Coordenador do Projeto de Pesquisa Direito Internacional do Trabalho e o resgate da dignidade e da cidadania. E-mail: florisbaldelolmo@gmail.com

2 Doutoranda em Direito pela Universidade Federal do Pará. Mestre em Direito pela Universidade Federal de Santa Maria. Integrante do Grupo de Pesquisa Direitos dos Povos e Comunidades Tradicionais - UFPA, do Grupo de Pesquisa em Direitos da Sociobiodiversidade - UFSM e, do Grupo de Pesquisa Tutela de Direitos e sua Efetividade - URI Santo Angelo.
} 
Falar a respeito da construção de um direito comum na contemporaneidade consiste em tarefa fadada à observação e averiguação das problemáticas que assolam os sistemas sociojurídicos como um todo no âmbito mundial. Portanto, carrega consigo grande complexidade a ser buscada pelas lentes por meio do qual se observa.

Sem dúvida alguma, o pensamento de Delmas-Marty é capaz de reconfigurar as noções doutrinárias construídas até então, trazendo uma nova realidade possível através da desnacionalização ou internacionalização do direito em prol dos valores universais.

É sob essa perspectiva que a presente análise se situa, ainda que superficialmente tendo em vista que se pretende tão somente a averiguação do pensamento de Delmas-Marty e autores afins como um todo, sem ater-se ao desenvolvimento de suas obras de maneira minuciosa -, em virtude da necessidade de aprofundamento de estudos acerca da questão para seu melhor desenvolvimento.

Assim, a pesquisa que aqui se desenvolve objetiva analisar os limites e possibilidades inerentes à construção de um direito comum em âmbito global, evidenciando-se a natureza eurocêntrica deste pensamento. Por consequência averigua-se a possibilidade de sua concretização, levando em conta as diferentes realidades em âmbito global a partir de uma análise da realidade latino-americana. Neste ponto, indispensável evidenciar o papel do novo constitucionalismo latino-americano enquanto movimento regional capaz de aproximar regionalmente os pensamentos acerca dos valores universais, de acordo com a identidade e necessidades próprias do continente.

Em decorrência, a reflexão proposta advém da seguinte problemática: Quais as possibilidades para a construção de um direito comum, levando em conta sua natureza eurocêntrica e as diferentes realidades sociojurídicas em âmbito global, a partir de uma análise das peculiaridades da América Latina e do papel do movimento denominado novo constitucionalismo latino-americano?

Para responder a esse questionamento a metodologia empregada obedece ao trinômio: Teoria de Base/Abordagem, Procedimento e Técnica. Como Teoria de Base e Abordagem optou-se pela perspectiva sistêmica utilizando-se autores com visão multidisciplinar e conectando diversos ares do saber. Os procedimentos elegidos foram a pesquisa bibliográfica e documental (em meios físicos e digitais - sites e redes sociais). A técnica empregada foi a construção de fichamentos e resumos estendidos. 
Dessa forma, a pesquisa que aqui se desenvolve está dividida em dois grandes capítulos, sistematicamente interligados: primeiramente pretende-se apresentar os principais pontos inerentes à construção de um direito comum, seus limites e possibilidades tendo em vista sua natureza eurocêntrica. Por conseguinte, procura-se evidenciar a realidade latinoamericana e a partir de então verificar-se métodos capazes de direcionar às várias regiões do globo para a construção de um direito comum.

\section{1 - A CONSTRUÇÃO DE UM DIREITO COMUM EM ÂMBITO GLOBAL: projeções} desde a América Latina

O fenômeno da mundialização e a insurgência de pensamentos alinhados para a construção de um direito comum, ${ }^{3}$ que considere a diversidade de culturas e identidades humanas a partir da harmonização de diversos sistemas jurídicos, consiste em paradigma inovador que pressupõe a congregação de elementos sociológicos, filosóficos e antropológicos pela de diversos ares do saber. Assim, se ultrapassam perspectivas conservadoras representadas pelo formalismo inserto na sistematização normativa, para então insurgir-se como a capacidade de gerar reflexões que vislumbrem os fenômenos jurídicos de forma sistêmica e complexa.

Nesse diapasão o advento da contemporaneidade, enquanto delimitação temporal que marca um novo rumo no modo de concretização das relações interpessoais - em virtude da propulsão do fenômeno da mundialização -, deflagra consequentemente novas relações sociojurídicas que ensejam a necessidade de se admitir novas formas de se compreender os fenômenos jurídicos. Por conseguinte, é necessária uma reconfiguração dos sistemas jurídicos, a ponto de se mostrarem como ordens propositoras, e não impositoras: ou seja, os comandos jurídicos partiriam de uma base conciliável pelos povos ao invés de serem impostos verticalmente, enquanto modo de padronização de comportamentos uníssonos.

Em suma, a dificuldade dessa busca de um direito "comum" deve-se menos ao obstáculo, mesmo forte, dos particularismos do que à ambiguidade que embasa o

\footnotetext{
3 Delmas-Marty propõe-se, então, a reinventar um "direito comum" que possibilite a conciliação da multiplicidade do que podemos conceber como sistemas jurídicos. Isso na tentativa de encontrar uma nova lógica harmônica para o sistema; nas palavras da autora, uma paisagem em ordem (paysage ordonné). Ao reconhecer que "o que está em jogo é o conteúdo das normas e não a existência delas" (p. 8), a autora organiza as três partes do livro com base em três clássicas perguntas existenciais: o que são os novos movimentos das normas, ou melhor, do que essa desordem está composta; como organizá-la; e, por fim, para que organizá-la. SANCHEZ, Michelle Ratton. Reflexão: Por um direito comum... In: Revista Direito GV, Vol. 01, N. 02, jundez. 2005, p. 202.
} 
procedimento. Pois a internacionalização do direito cria a ilusão de que o direito se torna comum, ao passo que comporta o duplo risco de deixá-lo mais opaco ainda aos não-juristas - portanto, de fortalecer a hegemonia dos profissionais do direito - e de impô-lo sob a pressão econômica ao conjunto dos países - portanto, de fortalecer a hegemonia dos países desenvolvidos. Logo, seria ingênuo acreditar que a internacionalização do direito e a complexidade crescente que o acompanha garantirão o advento de um direito comum em todos os sentidos do termo. ${ }^{4}$

Com a finalidade de elaborar um novo método que seja capaz de atingir um direito comum, a professora Mireille Delmas-Marty estabelece, ao longo do aperfeiçoamento de seu pensamento, diversas formas de reestruturação da interpretação e legitimação da norma para se chegar a inovações na leitura normativa. ${ }^{5}$ Consequentemente, enquanto desafio inserto nas inovações de leitura normativa, a autora salienta a necessidade de conciliação da questão econômica com os direitos humanos na esfera global, tarefa fadada aos juristas na contemporaneidade, de modo a não mais considerar economia e direitos humanos como ordens contrapostas com interferência prejudicial mútua, mas sim como ordens harmônicas.

Dessa forma, a construção de um direito comum perpassa necessariamente pela extinção de qualquer sobreposição impregnada na relação entre economia e direitos humanos. Nesse sentido, identifica-se a atuação dos tribunais e seu papel preponderante na construção de um direito comum em cenário global, por meio de métodos de interpretação que lhe são pertinentes e visam sumariamente reafirmar, de forma constante, o caráter contraposto existente entre economia e direitos humanos: a concorrência e a cooperação.

Pode-se afirmar que em decorrência do caráter economista que prevalece no fenômeno da mundialização perpetrada nos tribunais, prolifera a concorrência - a fim de legitimar questões meramente econômicas, se reconhece ou não a mundialização no âmbito jurisdicional de modo a se sobrepor a soberania estatal quando houver conveniência. No entanto, importa salientar que a necessidade de se vislumbrar a atuação jurisdicional em todas as acepções através do aspecto humanístico, sugere a cooperação enquanto meio para se

\footnotetext{
${ }^{4}$ DELMAS-MARTY, Mireille. Por um direito comum. São Paulo: Martins Fontes, 2004, p. 210.

${ }^{5}$ Um direito "comum" é, sobretudo, um direito acessível e, na medida do possível, acessível a todos. Isso pressupõe uma disciplina, quase uma deontologia, do trabalho legislativo, uma vez que é verdade que, "dentre todos os abusos do direito que nossa época protetora forcejou para combater, o abuso do direito de legislar teria merecido um lugar". O legislador deveria, de todo modo, preocupar-se em organizar entre a "lei e o povo" esse meio de comunicação do qual Portalis dizia que era necessário "a fim de que o povo saiba ou possa saber que a lei existe e que existe como lei”. DELMAS-MARTY, Mireille. Por um direito comum. p. 212.
} 
prevalecer a efetivação dos direitos do homem sobre o aspecto econômico, nos diálogos interjurisdicionais. $^{6}$

Assim, de acordo com Jânia Saldanha, admite-se que a concorrência está pautada em uma ética do modelo neoliberal, que, segundo Foucault, essa concorrência é o próprio elemento central que orienta o poder e a construção das instituições neoliberais (as quais por origem e funções são diversas do Poder Judiciário e das demais instituições, que devem primar pelos direitos do homem).

Dessa forma, observa-se que se vislumbrando o direito cosmopolítico de forma abstrata sob o prisma dos tribunais, o avanço da cooperação mostra-se como aspecto fundamental, cujos avanços - ainda que tímidos - já são perceptíveis. E é neste panorama de relativização da soberania estatal, enfraquecimento do Estado-nação e fortalecimento da cooperação mundial, via organizações internacionais, que o direito internacional alcançaria sua efetividade máxima: nesse ínterim a paz e a estabilidade internacionais seriam garantidas.

Adriana Beltrame e René Silva, ao analisarem os robustos argumentos de DelmasMarty, apontam como questão fundamental para o fortalecimento da cooperação entre tribunais - levando em conta a diversidade de interesses, culturas e necessidades em âmbito global - o fenômeno do pluralismo ordenado, justificando-se de acordo com as seguintes razões:

\begin{abstract}
A diversidade de culturas jurídicas dificulta, muitas vezes, a construção de tal comunidade. O problema é que esta diversidade gera certa desordem no direito internacional na medida em que a construção de valores ou conceitos com vocação universal é freada pelas diferenças. Entretanto, "é possível sair-se desta desordem, na tentativa de elaboração de uma teoria ao mesmo tempo dialética e de síntese, cujo objetivo seria, a partir da pluralidade de sistemas, construir um 'pluralismo ordenado"?
\end{abstract}

Nesse contexto, as possibilidades de abertura de diálogo entre as justiças dos Estados com as cortes não nacionais encontram no fortalecimento da cooperação, por intermédio dos fundamentos do pluralismo ordenado, terreno fértil para o contínuo estabelecimento. Tais

\footnotetext{
6 SALDANHA, Jânia Maria Lopes. Diálogos interjurisdicionais: um problema de cooperação ou de concorrência? Disponível em: <http://justificando.com/2015/03/30/dialogos-interjurisdicionais-um-problema-decooperacao-ou-de-concorrencia/> Acesso em: 13 mai. 2017.

${ }^{7}$ BELTRAME, Adriana; SILVA, René Marc da Costa. A cooperação jurídica e a internacionalização do direito como instrumento de ligação entre o local e o global no sistema mundo atual. Padê. Vol. 2, n. 2, Brasília: jul/dez. 2008. Disponível em: https://www.publicacoesacademicas.uniceub.br/pade/article/view/584/810 Acesso em: 13 mai. 2017.
} 
fundamentos pautam-se em movimentos de internacionalização do direito, a saber: harmonização e hibridação, ${ }^{8}$ os quais visam a conformar os sistemas jurídicos transnacionais enquanto forma de garantir e assegurar os direitos do homem e, por conseguinte, acenar para a possibilidade de um direito comum ou de uma ordem jurídica globalizada.

No momento em que essa realidade conflitual perpassa a seara dos tribunais para então se fazer presente na ordem global como um todo, ou melhor, indiscriminadamente nas relações sociojurídicas desencadeadas pelo fenômeno da mundialização, pode-se afirmar que:

\begin{abstract}
$\mathrm{Na}$ busca de um direito comum efetivo, que seja ao mesmo tempo universalista e pluralista, é necessário que se saiba "pensar o múltiplo". Para tanto, os juízes nacionais são desafiados a lançar mão de argumentos não mais fundados apenas no direito interno, mas advindos de marcos normativos regionais e internacionais e de jurisprudência produzida por seus pares estrangeiros de outros tribunais. Devem recorrer a novas lógicas que permitam encontrar respostas adequadas a esta nova realidade. Delmas-Marty propõe, nesse sentido, que se recorra a uma lógica de graduação, que poderá oferecer os suportes de um raciocínio que combine os princípios de hierarquia, identidade e conformidade. ${ }^{9}$
\end{abstract}

Todavia a tarefa de se pensar o múltiplo, como proposto por Delmas-Marty, carrega consigo, de forma intrínseca, a noção de valores e responsabilidades como pressuposto de toda e qualquer reconfiguração para um direito comum. Seja ela a partir de uma nova lógica nos diálogos interjurisdicionais que leve em conta a cooperação, seja ela pela redução da economia das relações sociojurídicas decorrentes da mundialização.

Isso se deve, tendo em vista que o papel que cabe ao mundo jurídico diz respeito ao reconhecimento de valores postos em conformidade com a relevância a eles atribuídas no plano sociopolítico mundial, para, a partir daí, verificar-se a amplitude da responsabilidade:

\footnotetext{
${ }^{8}$ A ideia de um "pluralismo ordenado" no plano internacional sugere a existência de determinados movimentos de internacionalização do direito. Estes movimentos são: a hibridação e a harmonização. Entende-se por harmonização o movimento pelo qual, imbuídos por uma norma de origem internacional (que pode ser um tratado internacional), os Estados veem-se na obrigação moral ou jurídica de reformar seu ordenamento jurídico, de modo que todos criem normas semelhantes ou quase idênticas. Se um determinado número de Estados adotar normas semelhantes, pressupõe-se que todos eles possam realizar a proteção de determinados direitos dentro de seus territórios. Esta harmonização facilitaria a cooperação jurídica entre tais Estados, afinal, a ideia da harmonização é justamente a de colocar princípios comuns entre os Estados, para facilitar a compatibilidade de um ordenamento jurídico com outro.

O segundo movimento, o da hibridação, pressupõe a criação de um corpo normativo supraestatal, o qual serviria para nortear todos os Estados. Seria como uma fusão dos direitos nacionais em um direito unificado. Sem dúvida este movimento ganha força, atualmente, com a criação dos tribunais penais internacionais e cortes de direitos humanos. Ao se criar estas cortes com competência para julgar indivíduos e Estados realiza-se, de forma indireta, a defesa dos valores proclamados universais. BELTRAME, A.; SILVA, R. M. C. Op. cit., p. 55-56.

9 SALDANHA, Jânia Maria Lopes; BRUM, Márcio Morais. A margem nacional de apreciação e sua (in)aplicação pela Corte Interamericana de Direitos Humanos em matéria de anistia: uma figura hermenêutica a serviço do pluralismo ordenado? Anuario Mexicano de Derecho Internacional. Vol. XV, 2015, p. 199.
} 
tanto no que se refere aos atores envolvidos, assim como no que refere à extensão da mesma. ${ }^{10}$ Com isso, tem-se como pressuposto promover o acesso comum ao direito por meio da consagração de valores transnacionais que ultrapassem os percalços advindos da mundialização.

\begin{abstract}
Isso quer dizer que o acesso ao direito não é forçosamente o acesso a todas as sutilezas técnicas da regra jurídica, mas pelo menos a possibilidade, por conhecer os princípios que as embasam, de fazer um juízo argumentado como cidadão e, como jurisdicionado, segundo a expressão do Tribunal Europeu dos Direitos do Homem no acórdão Malone contra o Reino Unido, já citado (1984), "de regrar sua conduta" e de "prever num grau razoável, nas circunstâncias da causa, as consequências que podem derivar de um determinado ato", cercando-se, "se necessário", diz ainda o Tribunal, de "conselhos esclarecidos".
\end{abstract}

Obviamente, o reconhecimento de valores postos na ordem mundial a ser feito pelo plano jurídico perpassa incessantemente pela seara da dicotomia entre economia e direitos humanos, refletindo assim a relevância concedida pela humanidade a valores que pendem ou pela economização ou pela humanização das relações sociais. Por consequência tal dicotomia reponta a dificuldade de se construir uma nova lógica harmônica para os diversos sistemas jurídicos vigentes e adjacências surgidas em virtude da economização das relações sociais.

A questão é que o surgimento de tais adjacências - aqui caracterizadas como a incorporação de regramentos derivados de outros poderes que não o legislativo, portanto normas que não possuem força de lei - acabam por legitimar a economia das relações sociais. Dessa forma, tais regramentos passam a fazer parte e garantir a eficácia de ações no campo sociojurídico sem que necessariamente estejam em conformidade com os comandos humanistas basilares para a continuidade da harmonia da vida e relações humanas no planeta, fortalecendo a discrepância entre os valores universais em questão. ${ }^{12}$ Em entrevista, DelmasMarty refere tal questão asseverando o seguinte:

\footnotetext{
${ }^{10} \mathrm{Na}$ perspectiva "responsabilizar os atores", extensão da responsabilidade, a multiplicação dos atores em si mesmos. Comecemos pela extensão da responsabilidade, se por acaso, se o julgamento Érika é levado em consideração atualmente, pois, ao fundo, podemos considerá-lo como o resultado de um longo processo de tomada de consciência na confluência do universalismo de valores e da globalização dos atores. Pode dizer-se, com efeito, que a globalização não cria propriamente falando, novos riscos, bem como não cria valores, mas tem por efeito acentuar o caráter grave e talvez irreversível de danos potenciais. Claramente, é o caso em matéria ambiental. DELMAS-MARTY, Mireille. Aula de Mireille Delmas-Marty no Collège de France. Tradução Livre: Leonardo de Camargo Subtil. Áudio Disponível em: http://www.collegedefrance.fr/default/EN/all/int_dro/ Acesso em: 18 dez. 2015.

${ }^{11}$ DELMAS-MARTY, Mireille. Por um direito comum. São Paulo: Martins Fontes, 2004, p. 218.

${ }^{12}$ Não se trata mais somente da dignidade própria a cada ser humano, mas da dignidade, pode-se dizer, como emblema desta comunidade inter-humana que acompanha a globalização. Em suma, tanto se ela significar recusa à desumanização do ser humano, como se ela significar a recusa à sua fabricação, pode-se afirmar que a recusa
} 
... os operadores econômicos são de longe os mais poderosos, quando se trata da produção de normas ou de sua aplicação. Os investidores privados podem processar os Estados por violação do direito dos investimentos diante de um órgão de arbitragem, o Centro Internacional para solução de controvérsias relativas aos investimentos (CIRDI). Mesmo na OMC, onde seu papel é mais indireto, pois as empresas não intervêm senão para fornecer informações (como amicus curiae, amigo da Corte), os Estados seguidamente figuram como seu porta-voz. Para responder ao seu questionamento, pode-se dizer, reforçando o que foi dito o direito econômico e comercial, dessa forma, ultrapassou os Direitos do Homem. (...) Entretanto, não basta liberar o comércio para proteger o conjunto dos Direitos do Homem. Bem ao contrário, alguns consideram que os dois fatores de internacionalização do direito - o universalismo dos valores e a globalização econômica - são apartados, até mesmo antinômicos. Haveria, de um lado, o direito à mundialização favorecendo as trocas econômicas e, de outro, uma mundialização do direito, vista como uma harmonização em torno de valores comuns. De minha parte, considero que é possível uma sinergia, muito embora isso seja dificultado, pois é muito difícil perceber que as organizações comerciais e financeiras não garantem o respeito aos direitos fundamentais e que o universalismo dos valores pode ser imposto de maneira hegemônica. ${ }^{13}$

Assim, para que se possa pensar na construção de um direito comum, deve-se ter em mente a necessidade de aparar tais arestas que impossibilitam em primeira instância a construção de um pensamento comum através da comunhão de ideias convergentes no que diz respeito aos valores universais. Por consequência, é necessário se pensar em uma valoração condizente no plano jurídico a partir daí, trabalhar-se no sentido de construção de uma ordem jurídica mundial harmônica.

Ainda que se tenha utilizado neste ensaio diversos autores que trabalham de maneira direta e indireta com a temática que aqui foi proposta, sabe-se que as digressões pertinentes à construção de um direito comum provêm neste trabalho, diretamente das ideias de DelmasMarty. No entanto, de acordo com a professora Michelle Ratton Sanchez, a grande problemática para a construção de um direito comum conforme os métodos propostos por Delmas-Marty, seria o fato de que tais métodos foram construídos tendo por base a realidade europeia, de forma que se coloca em xeque a possibilidade de se construir ou não, um direito

do desumano vai deflagrar um duplo processo de transformação de valores. De uma parte, a extensão dos DH à dignidade; de outra parte, o surgimento dos direitos da humanidade, mutação talvez ainda mais radical, pois ela poderia anunciar novos conflitos: o homem voltado contra a humanidade (DELMAS-MARTY, Mireille. Os direitos do homem: os valores universais em questão. Aula de Mireille Delmas-Marty no Collège de France. Áudio Disponível em: http://www.collegedefrance.fr/default/EN/all/int_dro/ Acesso em: 18 dez. 2015.

${ }^{13}$ DELMAS-MARTY, Mireille. Entrevista. Tradução Livre: Leonardo de Camargo Subtil. Lettre Du Collège de France, nº 22, fev. 2008. 
comum em escala global - levando em conta as divergências culturais, econômicas e de identidade existentes - sob uma perspectiva eurocêntrica. ${ }^{14}$

Todavia, há que se atentar para a relevância de questões geopolíticas que acabam por asseverar a problemática posta, colocando-se em evidência neste momento a situação da América Latina, enquanto continente integrante do chamado Sul Social, frente aos parâmetros eurocentristas e desenvolvimentistas do Primeiro Mundo os quais se classificam como elementos insertos no processo denominado como Nova Colonialidade.

Nesse sentido, resta saber como construir um direito comum levando em consideração as inúmeras adversidades do mundo sociojurídico já apresentadas, como a dicotomia existente entre economia e direitos humanos na atuação dos tribunais e nas relações sociojurídicas. Ademais há que se falar em questões pertinentes aos valores universais, sua economização, assim como as dificuldades para o advento de uma ordem harmônica frente às chamadas adjacências ao sistema jurídico, agregadas à realidade e necessidades latinoamericanas.

Sabe-se que a referida tarefa necessita de aprofundados estudos e uma reordenação de todo sistema posto, globalmente, no entanto cabe averiguar quais os parâmetros que poderão ser engendrados na América Latina, os quais sejam capazes de afastar o caráter de dependência inserto na Nova Colonialidade. Tais ações são fundamentais para que ocorra o reconhecimento da identidade, necessidades e peculiaridades do continente e então, a partir daí, se pensar em subsídios capazes de auxiliar para a construção de um direito comum, partindo das concepções latino-americanas.

\section{2 - A CONTRUÇÃO DE UM DIREITO COMUM E A NOVA COLONIALIDADE LATINO-AMERICANA: projeções para a América Latina}

No momento em que se pretende analisar elementos para a construção de um direito comum, é indispensável revisitar as disparidades regionais que circunscrevem as relações interestatais no globo. Assim, considerando que as lentes de observação que conduzem a

\footnotetext{
${ }^{14}$ As referências da autora sugerem uma crítica recorrente em trabalhos do gênero: pretender o comum a partir do eurocentrismo. A própria autora reconhece a concentração de sua análise na experiência europeia. Se, por um lado, o conteúdo do livro não consegue resistir a essa crítica, por outro, a autora instiga a questão: será que é possível confirmar suas pretensões normativas a partir de outras realidades sociojurídicas? SANCHEZ, Michelle Ratton. Reflexão: Por um direito comum... In: Revista Direito GV, Vol. 01, N. 02, jun- dez. 2005, p. 205.
} 
presente pesquisa são lentes periféricas, desde a América Latina, registrar-se-á, a partir de então, questões cruciais para entender a inviabilidade da construção de um direito comum que abarque as pretensões contrapostas e incongruentes entre si, entre Centro-Periferia, principalmente no que concerne à valorização de direitos humanos e minimização do caráter economicista das relações.

Veja-se que isso se afirma tendo em vista que as pretensões humanistas e econômicas em âmbito global dividem-se de forma abissal entre aquelas provindas do centro e aquelas provindas da periferia. Assim, levando em conta que a conquista dos auspícios do Norte Social depende em muito dos sacrifícios do Sul Social, resta evidenciar a situação geopolítica que não permite a desconsideração das peculiaridades e da historicidade periférica, neste caso restringindo-se à América Latina, para que possa vislumbrar os desafios pertinentes a construção de um direito comum em âmbito global. ${ }^{15}$

Nesse ínterim, é fundamental observar que a história da América Latina demonstra de forma muito clara o caráter de submissão atribuído ao continente, frente aos países ditos desenvolvidos. Em meio a tal condição que se perpetua desde a colonização do continente latino-americano, a imposição do desenvolvimentismo e a definição de padrões eurocêntricos em diversas searas, acaba por atender os interesses hegemônicos de países desenvolvidos, os quais têm a periferia como território livre para exploração e imposição de paradigmas que lhe são caros.

\footnotetext{
${ }^{15}$ Imprescindível nesse momento, asseverar os elementos que traduzem o abismo existente entre centro-periferia, Norte Social e Sul Social, nas palavras de Boaventura de Sousa Santos: definidos, assim, de acordo com a perspectiva social, não levando em conta tão somente os aspectos geográficos: Desde mi punto de vista, las Epistemologías del Sur son el reclamo de nuevos procesos de producción, de valorización de conocimientos válidos, científicos y no científicos, y de nuevas relaciones entre diferentes tipos de conocimiento, a partir de las prácticas de las clases y grupos sociales que han sufrido, de manera sistemática, destrucción, opresión y discriminación causadas por el capitalismo, el colonialismo y todas las naturalizaciones de la desigualdad en las que se han desdoblado; el valor de cambio, la propiedad individual de la tierra, el sacrificio de la madre tierra, el racismo, al sexismo, el individualismo, lo material por encima de lo espiritual y todos los demás monocultivos de la mente y de la sociedad -económicos, políticos y culturales- que intentan bloquear la imaginación emancipadora y sacrificar las alternativas. En este sentido, son un conjunto de epistemologías, no una sola, que parte de esta premisa, y de un Sur que no es geográfico, sino metafórico: el Sur antiimperial. Es la metáfora del sufrimiento sistemático producido por el capitalismo y el colonialismo, así como por otras formas que se han apoyado en ellos como, por ejemplo, el patriarcado. Es también el Sur que existe en el Norte, lo que antes llamábamos el tercer mundo interior o cuarto mundo: los grupos oprimidos, marginados, de Europa y Norteamérica. También existe un Norte global en el Sur; son las elites locales que se benefician del capitalismo global. Por eso hablamos de un Sur antiimperial. Es importante que observemos la perspectiva de las Epistemologías del Sur desde este punto de partida. SANTOS, Boaventura de Sousa. Introducción: las epistemologías del Sur: In: CIDOB (org.). Formas-Otras. Saber, nombrar, narrar, hacer. Barcelona: CIDOB Ediciones, 2011, p. 16.
} 
Diante desse quadro, restam prejudicadas todas as formas de reconhecimento próprio de cultura e identidade latino-americanas em virtude da submissão que atrela a América Latina a ditames pós-coloniais reveladores do surgimento de uma Nova Colonialidade. ${ }^{16}$ Por conseguinte, imposições ideológicas fazem com que os parâmetros eurocêntricos e aqueles provenientes de uma racionalidade puramente econômica - característica própria dos países de primeiro mundo - sejam capazes de difundir uma visão única e reducionista da ideia de desenvolvimento, privilegiando a economização das relações sociojurídicas e a unicidade do saber.

Portanto, enquanto território subserviente, mas indispensável ao sistema capitalista, a América Latina consiste em região periférica do globo a qual os ditames eurocêntricos soam como comandos do modo de vida a serem transcritos para a realidade latino-americana. Disso decorre a construção de pensamentos latinos que rejeitam a historicidade e a identidade do continente, em prol da importação de elementos históricos e identitários que não lhe são próprios, mas que são tidos universalmente como corretos e aceitáveis.

Obviamente não se pode olvidar que a história sociojurídica dos países que compõem a América Latina é permeada por dois pontos cruciais: o primeiro diz respeito ao ímpeto social dos povos latino-americanos por adequar a ordem constitucional à realidade vivida no continente e às necessidades prementes dos cidadãos latinos na contemporaneidade; já o segundo nos demonstra de forma inequívoca a influência direta que os países colonizadores exerceram (e talvez ainda exerçam) na formação jurídica dos países que compõem o território latino-americano, que demonstra ainda no momento atual, sua essência desenvolvimentista. ${ }^{17}$

\footnotetext{
${ }^{16}$ Para elucidar os desdobramentos sociopolíticos desse processo, Quijano (1997) cunhou o conceito de colonialidade, como algo que transcende as particularidades do colonialismo histórico e que não desaparece com a independência ou descolonização. Essa formulação é uma tentativa de explicar a modernidade como um processo intrinsecamente vinculado à experiência colonial. Essa distinção entre colonialidade e colonialismo permite, portanto, explicar a continuidade das formas coloniais de dominação, mesmo após o fim das administrações coloniais, além de demonstrar que essas estruturas de poder e subordinação passaram a ser reproduzidas pelos mecanismos do sistema-mundo capitalista colonial-moderno. Dessa maneira, a noção de colonialidade atrela o processo de colonização das Américas à constituição da economia-mundo capitalista, concebendo ambos como partes integrantes de um mesmo processo histórico iniciado no século XVI (CASTROGOMEZ; GOSFROGUEL, 2007). ASSIS, Wendell Ficher Teixeira. Do colonialismo à colonialidade: expropriação territorial na periferia do capitalismo. In: Caderno CRH, v. 27, n. 72. Salvador: set-dez. 2014. Disponível em: http://www.scielo.br/pdf/ccrh/v27n72/11.pdf Acesso em: 15 set. 2016, p. 614.

${ }^{17}$ A fim de corroborar os argumentos antes expendidos, veja-se a lição de Cenci e Bedin: ... cabe destacar a diferença (e, mais do que isso, a desigualdade) existente entre os lugares historicamente ocupados, por exemplo, pela Europa e pela América Latina, o que se reflete, evidentemente, nas histórias constitucionais: se, de um lado, o constitucionalismo europeu conviveu tranquilamente com a manutenção de colônias de exploração (o que evidencia uma absurda dissintonia entre os discursos constitucionais europeus e as práticas disseminadas no âmbito das colônias), os países latino-americanos estiveram, de outro lado, na condição de explorados cultural e
} 
El hecho colonial colocó a los pueblos originarios en una posición subordinada. Sus territorios y recursos fueron objeto de expolio y expropiación por terceros; su mano de obra fue explotada, y hasta su destino como pueblos fue alienado de sus manos. La ideología de la "inferioridad natural de los indios" y la figura jurídica de la tutela indígena permitieron estabilizar a lo largo del tiempo el modelo de subordinación indígena. La independencia política de las colonias americanas respecto de las metrópolis no significó el fin de esa subordinación. Los nuevos estados latinoamericanos se organizaron bajo flamantes Constituciones liberales, pero con proyectos neocoloniales de sujeción Indígena. ${ }^{18}$

Nesse sentido, importa referir as lições de Jânia Saldanha e Marcio Brum quando afirmam que na contemporaneidade pode-se observar a ocorrência de um processo duplo na seara do direito constitucional: o primeiro diz respeito à constitucionalização do direito internacional; e o segundo diz respeito à internacionalização do direito constitucional, ou sua desnacionalização. ${ }^{19}$

Sem dúvida, tal processo reflete a realidade constitucional latino-americana na atualidade, tendo em vista que o movimento denominado novo constitucionalismo latinoamericano tem o condão de modificar positivamente a ordem constitucional da maioria dos países da América Latina, a fim de adequar os ordenamentos constitucionais à realidade e à historicidade do continente. Os autores prosseguem a análise referindo que o processo de internacionalização do direito constitucional ou de desnacionalização consiste no reconhecimento em âmbito do direito internacional de determinadas funções materialmente constitucionais. Salientam ainda que:

Esses movimentos circulares de abertura recíproca que colocam sob interrogação os limites impostos pelas fronteiras nacionais, bem como a propalada autonomia do direito internacional, conduzem, inevitavelmente, ao reconhecimento de que o

economicamente. Enquanto os países europeus e os Estados Unidos da América incorporavam politicamente os ideais liberais, consolidando o Estado de Direito e as Constituições nacionais, fundadas em processos revolucionários, a América Latina ostentava uma realidade social escravagista, desigual e uma organização política absolutamente subordinada aos países europeus colonizadores - especificamente, no caso, Espanha e Portugal. CENCI, Ana Righi; BEDIN, Gilmar Antônio. O Constitucionalismo e sua Recepção na América Latina, Uma leitura das fragilidades do Estado constitucional na região e suas novas possibilidades de realização. In: Direitos Emergentes na Sociedade Global - Anuário do Programa de Pós-Graduação em Direito da UFSM, 2013, p. 29.

${ }^{18}$ FAJARDO, Raquel Z. Yrigoyen. El horizonte del constitucionalismo pluralista: del multiculturalismo a la descolonización. In: El derecho en América Latina: un mapa para el pensamiento jurídico del siglo XXI. GARAVITO, César Rodríguez (org.). Buenos Aires: Siglo Veintiuno Editores, 2011, p. 138.

${ }^{19}$ SALDANHA, Jânia Maria Lopes; BRUM, Márcio Morais. A margem nacional de apreciação e sua (in)aplicação pela Corte Interamericana de Direitos Humanos em matéria de anistia: uma figura hermenêutica a serviço do pluralismo ordenado? Anuario Mexicano de Derecho Internacional. Vol. XV, 2015, p. 197. 
nacional não se sustém sozinho, quanto parece "ser nacional o futuro do direito internacional" diante da sua influência sobre as ordens nacionais. ${ }^{20}$

Obviamente, não se pode olvidar que diante da historicidade que rege o continente latino-americano, torna-se impossível negar ou desconsiderar a influência europeia que se perpetuou nas normas jurídicas dos países que o compõe, assim como a apropriação por estes, de costumes e ideais que não eram (ou não são) os seus. ${ }^{21}$ Assim, ainda que não atenda integralmente aos anseios normativos do continente - tendo em vista suas peculiaridades enquanto fruto do desenvolvimentismo - o neoconstitucionalismo consubstanciou-se durante longo tempo como base teórica e estrutural dos ordenamentos constitucionais da América Latina, servindo ainda como norteador formal para o desenvolvimento do novo constitucionalismo latino-americano.

Frente a essas considerações, pode-se afirmar que, visando contrapor a lógica eurocêntrica impregnada nos ditames sociojurídicos da América Latina, conflitos de ordem sociológica passam a emoldurar uma nova fase constitucional no continente, a qual pretende aproximar a realidade e as peculiaridades latino-americanas dos comandos constitucionais. Assim, o movimento denominado novo constitucionalismo latino-americano configura-se como aporte sociojurídico empoderador, capaz de contrapor imperativos jurídicos emanados do Norte Social historicamente.

Em contexto similar ao do Caracaço, inserem-se, também, a chamada "Guerra do Gás” (em 2003, na Bolívia) e os protestos ocorridos no Equador (2005). Reunidas, as três revoltas populares foram o estopim de um movimento jurídico batizado com o nome de "Novo Constitucionalismo Latino-Americano" ou "Un constitucionalismo sin Padres". Esse novo constitucionalismo parece ter seu marco

\footnotetext{
${ }^{20}$ SALDANHA, J. M. L.; BRUM, M. M. Op. cit. p. 197.

${ }^{21}$ As concepções europeias normativas e sociais que constituíram a colonização da América Latina, apesar de influenciar diretamente nos costumes e regras utilizados na região por séculos, serviram como alicerces basilares para que o povo latino fosse capaz de construir sua própria identidade. No que se refere aos costumes em geral e no que tange ao modo de organização política e social, o continente latino figurou como importador nato das tradições europeias. Porém, essa reprodução da vida europeia efetuou-se em virtude das características impositoras que advieram da colonização, tendo em vista a inexistência de liberdade dos indivíduos que compuseram o povo latino em um primeiro momento. Assim, basta um exame perfunctório na história da colonização da América Latina, para que se constate a incompatibilidade entre o modo de vida imposto e a realidade fática vivenciada na América Latina. Isso ocorreu porque os colonizadores, desde o início da colonização, estabeleceram regras de governo e organização política com características eminentemente europeias, buscando tão somente atender os interesses daqueles que detinham o poder e que nem de longe representavam os interesses da população local. Por consequência, a América Latina passou a ser palco da situação de vulnerabilidade de seus cidadãos, com grande número de pessoas vivenciando condições de extrema pobreza e exclusão social, situação incentivada pela subordinação a que o continente latino se submeteu em relação aos países colonizadores. ARAÚJO, Marigley Leite de; MARTINS, Evilhane Jum. O novo constitucionalismo latino-americano e sua correlação com as modificações fáticas e estruturais do Direito Constitucional de Família. In: DEL'OLMO, Florisbal de Souza; BEDIN, Gilmar Antonio; ARAÚJO, Marigley Leite de (orgs.). Direito e Interação na América Latina. T. 2. Campinas, Millennium: 2015, p. 36-37.
} 
zero normativo com a promulgação da Constituição da República Bolivariana da Venezuelana (1999), desdobrando-se e desenvolvendo-se com as novas constituições do Equador (2008) e da Bolívia (2009). Suas raízes históricas, contudo, são mais profundas, e penetram séculos de história sul-americana e mundial. Nesse sentido, o novo constitucionalismo parte de postulados clássicos da teoria constitucional, repetindo, por exemplo, o tradicional catálogo de direitos de proteção individual. Por outro lado, procura superar o constitucionalismo clássico no que este não teria avançado, sobretudo no que se refere às possibilidades de articulação e releitura da categoria soberania popular, como condição necessária de legitimação das instituições e de gestão do próprio Estado. Indo mais longe, o Estado deverá ser refundado sobre os escombros das promessas liberais não cumpridas, promovendo-se sua reconstrução a partir de uma "nova geometria do poder". 22

Nesse ínterim, por meio de lutas sociais que objetivariam promover o reconhecimento da identidade dos povos pela figura estatal, o arcabouço constitucional da América Latina passa a ser constantemente transformado. A aproximação da realidade do continente com as cartas constitucionais originam um processo sociojurídico que permite o avanço da legislação constitucional em contextos nos quais os elementos constitucionais eurocêntricos até então vigentes, mostraram-se estagnados.

Em verdade, esse movimento constitucional é capaz de revelar uma imbricação de elementos próprios do novo constitucionalismo latino-americano, pois, ao mesmo tempo em que se está diante de processos constitucionais próprios de cada Estado, levando em conta questões atinentes à soberania e aos aspectos internos de cada país; se está também diante de problemáticas comuns à América Latina, de forma que qualquer ferramenta constitucional inerente à resolução de problemas sociopolíticos ou econômicos internamente ressoam as diversas questões próprias da colonialidade imposta ao continente como um todo.

Sob tais aspectos, objetivando-se reconhecer o novo constitucionalismo latinoamericano como um movimento constitucional que tem por escopo promover a integração do continente com vistas ao seu reconhecimento identitário, tem-se a plurinacionalidade ${ }^{23}$ enquanto pressuposto de tal movimento constitucional. $\mathrm{O}$ reconhecimento da

\footnotetext{
${ }^{22}$ VIEIRA, José Ribas; RODRIGUES, Vicente A. C. Refundar o Estado: o novo constitucionalismo latinoamericano. Disponível em: http://www.direito.ufg.br/up/12/o/24243799-UFRJ-Novo-ConstitucionalismoLatino-Americano.pdf?1352146239 - Acesso em: 13 mai. 2017. p. 02.

${ }^{23}$ los grupos sociales en situaciones en que los derechos individuales de las personas que los integran resultan ineficaces para garantizar el reconocimiento y la persistencia de su identidad cultural o el fin de la discriminación social de que son víctimas. Como lo demuestra la existencia de varios Estados plurinacionales (Canadá, Bélgica, Suiza, Nigeria, Nueva Zelanda, etc.), la nación cívica puede coexistir con varias naciones culturales dentro del mismo espacio geopolítico, del mismo Estado. El reconocimiento de la plurinacionalidad conlleva la noción de autogobierno y autodeterminación, pero no necesariamente la idea de independencia. SANTOS, Boaventura de Sousa. Refundación del Estado en América Latina: perspectivas desde una epistemología del Sur. Lima: Instituto Internacional de Derecho y Sociedad, 2010, p. 81.
} 
plurinacionalidade enquanto paradigma constitucional na América Latina se revela como condicionante, além de elemento eficaz para a concretização de uma integração regional que se idealiza. Por consequência, a insurgência de novos parâmetros regionais que evidenciem em suas legislações constitucionais ideais que primam pela efetiva descolonização do território e consequente integração de seus povos, a fim de fortalecer a identidade e resgatar os aspectos culturais originários do povo da América Latina, é tarefa fadada ao novo constitucionalismo latino-americano. ${ }^{24}$

As tendências atuais da América Latina remetem sem dúvida alguma, à união dos estados latino-americanos visando à congregação de esforços para a construção de uma nova ordem política e social que preze o reconhecimento da identidade e cultura de seus povos, inerente ao processo de descolonização e a uma nova ideia de desenvolvimento. Nesse ponto, vê-se que a construção de um direito comum em âmbito global, necessita precipuamente ultrapassar métodos sumariamente eurocêntricos para considerar a realidade de outros povos, outras culturas e outros valores, a ponto de o direito comum ser efetivamente comum globalmente, onde o comum seja sinônimo de universalidade.

Para tanto, os desafios em âmbito mundial devem ser encarados mutuamente, sem que haja a sobreposição de interesses com a promoção da igualdade em todas as acepções. Nesse diapasão, focos regionais de movimentos que aproximem os sentidos atribuídos a valores universais entre países, fortalecendo a humanização do direito em detrimento de sua economização mostram-se como elementos fundamentais para a construção de um direito comum.

\section{CONSIDERAÇÕES FINAIS}

As considerações efetuadas neste ensaio evidenciam as seguintes proposições: primeiramente, que a natureza eurocêntrica do pensamento inerente à construção de um

\footnotetext{
${ }^{24}$ Sin embargo, las reformas constitucionales también permiten expresar la resistencia proveniente de los antiguos y los nuevos colonialismos. Los contextos complejos donde se gestan las reformas imponen sus tensiones y sus contradicciones (aparentes o reales) a los textos constitucionales, lo que exige una interpretación pluralista para salvar sus limitaciones y resolver las tensiones de manera favorable a la realización de los objetivos y principios del proyecto constitucional pluralista. Ese ejercicio de interpretación es un ejercicio de poder $\mathrm{y}$, por ende, un ejercicio ahora también compartido por los pueblos indígenas en el marco del Estado plurinacional. FAJARDO, Raquel Z. Yrigoyen. El horizonte del constitucionalismo pluralista: del multiculturalismo a la descolonización. In: GARAVITO, César Rodríguez (org.). El derecho en América Latina: un mapa para el pensamiento jurídico del siglo XXI. Buenos Aires: Siglo Veintiuno Editores, 2011, p. 141.
} 
direito comum - além das problemáticas que dizem respeito a todos os sistemas jurídicos universalmente -, tornam-se ineficazes quando se observam as disparidades existentes entre as regiões do globo, sejam elas culturais, políticas, econômicas ou jurídicas.

Em um segundo momento, verifica-se que a construção de um direito comum na contemporaneidade necessita muito aquém de estratégias jurídicas globais para o estabelecimento dos verdadeiros valores universais, mas sim de um agir local, que somado a outras ações globais em sentidos convergentes, possam apresentar os mesmos sentidos aos valores universais: seja nas relações sociojurídicas, estatais, interestatais ou entre tribunais.

Nesse diapasão, no âmbito da América Latina, o novo constitucionalismo latinoamericano consiste em movimento que vem surgindo no continente enquanto mudança paradigmática que visa implementar parâmetros de descolonização e reaproximação das características originárias dos povos latinos em sua essência, através da plurinacionalidade e de ideais de integração entre os povos latino-americanos, visando ao bem comum por meio de ordenamentos constitucionais que tenham como prioridade o estabelecimento de valores congruentes entre si, que levem em conta a originalidade e as necessidades de seu povo.

Esse novo modelo constitucional latino-americano é fruto de reivindicações de comunidades locais, que em todo contexto histórico existente até a atualidade tiveram sua identidade sociocultural própria excluída do cenário global.

Dessa forma, buscando-se sanar a indagação que induziu a presente pesquisa, tem-se que o novo constitucionalismo latino-americano - enquanto movimento sociojurídico regional que visa reconhecer, garantir e legitimar os direitos de seus povos por meio do reconhecimento de sua identidade e necessidades - é capaz de demonstrar que movimentos sociojurídicos regionais neste sentido, que diminuam as diferenças e promovam a igualdade, são de grande valia, senão fundamentais, para a construção de um direito comum: agindo-se localmente para se pensar globalmente.

Em vista de tais argumentos, a construção de um direito comum perpassa e se distancia de uma perspectiva unicamente eurocêntrica, tendo a necessidade de movimentos regionais capazes de elencarem localmente os valores universais, a fim de que haja uma aproximação global de tais valores e o fortalecimento das relações sociojurídicas regionais a fim de se considerar neste ponto, suas peculiaridades e necessidades.

\section{REFERÊNCIAS}


ARAÚJO, Marigley Leite de; MARTINS, Evilhane Jum. O novo constitucionalismo latinoamericano e sua correlação com as modificações fáticas e estruturais do Direito Constitucional de Família. In: DEL'OLMO, Florisbal de Souza; BEDIN, Gilmar Antonio; ARAÚJO, Marigley Leite de (orgs.). Direito e Interação na América Latina. T. 2. Campinas: Millennium: 2015, p. 31-44.

ASSIS, Wendell Ficher Teixeira. Do colonialismo à colonialidade: expropriação territorial na periferia do capitalismo. In: Caderno CRH, v. 27, n. 72. Salvador: set-dez. 2014. Disponível em: http://www.scielo.br/pdf/ccrh/v27n72/11.pdf Acesso em: 15 set. 2016.

BELTRAME, Adriana; SILVA, René Marc da Costa. A cooperação jurídica e a internacionalização do direito como instrumento de ligação entre o local e o global no sistema mundo atual. Padê. Vol. 2, n. 2, Brasília: jul/dez. 2008. Disponível em: https://www.publicacoesacademicas.uniceub.br/pade/article/view/584/810 - Acesso em: 13 mai. 2017.

CASTRO-GÓMEZ, Santiago; GROSFOGUEL, Ramón (comps.). El giro decolonial: reflexiones para una diversidad epistémica más allá del capitalismo global. Bogotá: Siglo del Hombre Editores; Universidad Central, Instituto de Estudios Sociales Contemporáneos y Pontificia Universidad Javeriana, Instituto Pensar, 2007.

CENCI, Ana Righi; BEDIN, Gilmar Antônio. O Constitucionalismo e sua Recepção na América Latina: Uma leitura das fragilidades do Estado constitucional na região e suas novas possibilidades de realização. In: Direitos Emergentes na Sociedade Global - Anuário do Programa de Pós-Graduação em Direito da UFSM, 2013.

DELMAS-MARTY, Mireille. Aula de Mireille Delmas-Marty no Collège de France. Tradução Livre: Leonardo de Camargo Subtil. Áudio Disponível em: http://www.collegedefrance.fr/default/EN/all/int_dro/ Acesso em: 18 dez. 2015.

DELMAS-MARTY, Mireille. Entrevista. Tradução Livre: Leonardo de Camargo Subtil. Lettre Du Collège de France, $n^{\circ}$ 22, fev. 2008.

DELMAS-MARTY, Mireille. Os direitos do homem: os valores universais em questão. Aula de Mireille Delmas-Marty no Collège de France. Áudio Disponível em: http://www.collegedefrance.fr/default/EN/all/int_dro/ Acesso em: 18 dez. 2015.

DELMAS-MARTY, Mireille. Por um direito comum. São Paulo: Martins Fontes, 2004.

FAJARDO, Raquel Z. Yrigoyen. El horizonte del constitucionalismo pluralista: del multiculturalismo a la descolonización. In: GARAVITO, César Rodríguez (org.). El derecho en América Latina: un mapa para el pensamiento jurídico del siglo XXI. Buenos Aires: Siglo Veintiuno Editores, 2011.

QUIJANO, Aníbal. Modernidad, identidad y utopía en América Latina. Lima: Sociedad y Política, 1988. 
SALDANHA, Jânia Maria Lopes; BRUM, Márcio Morais. A margem nacional de apreciação e sua (in)aplicação pela Corte Interamericana de Direitos Humanos em matéria de anistia: uma figura hermenêutica a serviço do pluralismo ordenado? Anuario Mexicano de Derecho Internacional. Vol. XV, 2015.

SALDANHA, Jânia Maria Lopes. Diálogos interjurisdicionais: um problema de cooperação ou de concorrência? Disponível em: <http://justificando.com/2015/03/30/dialogosinterjurisdicionais-um-problema-de-cooperacao-ou-de-concorrencia/> Acesso em: 13 mai. 2017.

SANCHEZ, Michelle Ratton. Reflexão: Por um direito comum... In: Revista Direito GV, Vol. 01, N. 02, jun-dez. 2005.

SANTOS, Boaventura de Sousa., Introducción: las epistemologías del Sur in CIDOB (org.), Formas-Otras. Saber, nombrar, narrar, hacer. Barcelona: CIDOB Ediciones, 2011.

SANTOS, Boaventura de Sousa. Refundación del Estado en América Latina: perspectivas desde una epistemología del Sur. Lima: Instituto Internacional de Derecho y Sociedad, 2010.

SOUSA, Adriano Corrêa de. A libertação como objetivo central do novo constitucionalismo latino-americano: os caminhos para um constitucionalismo da libertação. Disponível em: http://www.publicadireito.com.br/artigos/?cod=3bd7ef30b1a12dc7 Acesso em: 13 mai. 2017.

VIEIRA, José Ribas; RODRIGUES, Vicente A. C. Refundar o Estado: o novo constitucionalismo latino-americano. Disponível em: http://www.direito.ufg.br/up/12/o/24243799-UFRJ-Novo-Constitucionalismo-LatinoAmericano.pdf?1352146239 - Acesso em: 13 mai. 2017. 